\title{
СОВРЕМЕННОЕ СОСТОЯНИЕ И ПЕРСПЕКТИВЫ РАЗВИТИЯ РЫНКА МОЛОКА И МОЛОЧНОЙ ПРОДУКЦИИ В МОСКОВСКОЙ ОБЛАСТИ
}

\author{
(c) 2018 Сурай Наталья Михайловна \\ кандидат технических наук, доцент кафедры экономики и управления \\ Московский государственный университет технологий и управления имени К.Г. Разумовского (ПКУ) \\ 109004, г. Москва, Земляной вал, д. 73 \\ (C) 2018 Бобков Александр Николаевич \\ доктор философских наук, профессор кафедры экономики и управления \\ Московский государственный университет технологий и управления имени К.Г. Разумовского (ПКУ) \\ 109004, г. Москва, Земляной вал, д. 73 \\ (c) 2018 Жукова Наталья Викторовна \\ кандидат экономических наук, доцент \\ и.о. директора департамента по учебно-методической работе \\ Московский государственный университет технологий и управления имени К.Г. Разумовского (ПКУ) \\ 109004, г. Москва, Земляной вал, д. 73 \\ (c) 2018 Абрамов Юрий Викторович \\ кандидат философских наук, доцент \\ и.о. зав.кафедрой «Гражданско-правовые дисциплины» \\ Московский государственный университет технологий и управления имени К.Г. Разумовского (ПКУ) \\ 109004, г. Москва, Земляной вал, д. 73

\section{(c) 2018 Федоров Борис Константинович} \\ кандидат экономических наук \\ доцент кафедры экономики и управления \\ Московский государственный университет технологий и управления имени К.Г. Разумовского (ПКУ) \\ 109004, г. Москва, Земляной вал, д. 73
}

Рассматриваются основные проблемы, сдерживающие развитие молочной отрасли и основные направления развития рынка молока и молочной продукции в Московской области.

Ключевые слова: Московская область, рынок молока и молочной продукции, государственная поддержка, поголовье молочного стада, продуктивность.

Московская область - один из лидирующих регионов-производителей продукции молочного животноводства в Российской Федерации. Рынок молока и молочных продуктов - важная составная часть продовольственного рынка Российской Федерации. Возрастающее значение молока как полноценного продукта питания и как сырьевого материала привело к увеличению спроса на него. В результате этого производство молока стало одной из важнейших отраслей сельскохозяйственного производства.

Молочная отрасль является ведущей в агропромышленном комплексе Московской области и выполняет задачу по обеспечению населения области, Москвы и других регионов России продукцией первой необходимости. Область занимает первое место в Центральном федеральном округе России по объемам производства молока и сыра, что вносит существенный вклад в обеспечение продовольственной безопасности страны.

K основным проблемам, сдерживающим развитие молочной отрасли, относятся снижение объемов производства молочного сырья, сезонность производства, низкий удельный вес молочного сырья высшего сорта, недостаток холодильных установок на молочных фермах, а также физический и моральный износ основных фондов молокоперерабатывающих заводов, большая часть которых не соответствует современным требованиям по энергоэффективности и экологии.

В 2017 г. в Московской области произведено 644,3 тыс.тонн молока, в т.ч. товарно- 
го $-574,7$ тыс.тонн, что составляет $2 \%$ от общего объема молока, произведенного в Центральном Федеральном округе, и около $2 \%$ от общего объема молока, произведенного в Российской Федерации. По итогам 2017 г. область занимает второе место в рейтинге регионов Центрального федерального округа по объемам производства молока (табл. 1) [1]. Товарность произведенного молока в области составляет 95,5\%. Московская область - один из крупнейших регионов-потребителей молока в России [2].

По данным табл. 1 можно отметить, что в Центральном федеральном округе Воронежская, Московская и Белгородская области занимают лидирующие позиции по объемам производства молока.

По итогам 2017 г. Московская область в Российской Федерации занимает шестое место по производству молока в сельскохозяйственных организациях и крестьянско-фермерских хозяй- ствах (после Татарстана, Краснодара, Башкирии, Удмуртии и Алтайского края), а в Центральном федеральном округе - второе место.

Основными производителями молока в области являются сельскохозяйственные организации. Общий объем производства молока в данном сегменте хозяйств составил 574,7 тыс.тонн (рис. 1). На долю личных подсобных хозяйств населения приходится около 7,7\% и на крестьянско-фермерские хозяйства - 3\%. В 2018 году в области планируется произвести 682 тысячи тонн молока [2].

Основная причина проблем с молоком - сокращение его производства в хозяйствах населения.

Поголовье коров в Московской области за период 2012-2017 гг. оставалось примерно на одном уровне (табл. 2).

Крестьянские (фермерские) хозяйства единственный сегмент, в котором постоянно уве-

Таблица 1. Динамика производства молока в хозяйствах всех категорий по Российской Федерации, Центральному федеральному округу за 2015-2017 гг.

\begin{tabular}{|c|c|c|c|c|c|c|c|c|c|}
\hline \multirow[b]{2}{*}{ Наименование } & \multicolumn{3}{|c|}{2015 г. } & \multicolumn{3}{|c|}{2016 г. } & \multicolumn{3}{|c|}{2017 г. } \\
\hline & $\begin{array}{l}\text { тыс. } \\
\text { тонн }\end{array}$ & $\begin{array}{c}\text { в \% } \\
\text { к итогу }\end{array}$ & $\begin{array}{c}\text { в расчете } \\
\text { на душу } \\
\text { населе- } \\
\text { ния, кг. }\end{array}$ & $\begin{array}{l}\text { тыс. } \\
\text { тонн }\end{array}$ & $\begin{array}{c}\text { в \% } \\
\text { к итогу }\end{array}$ & $\begin{array}{c}\text { в расчете } \\
\text { на душу } \\
\text { населе- } \\
\text { ния, кг. }\end{array}$ & $\begin{array}{l}\text { тыс. } \\
\text { тонн }\end{array}$ & $\begin{array}{c}\text { в\% } \\
\text { к итогу }\end{array}$ & $\begin{array}{c}\text { в расчете } \\
\text { на душу } \\
\text { населе- } \\
\text { ния, кг. }\end{array}$ \\
\hline РФ & 30781,1 & - & 215 & 30754,2 & - & 210 & 31100,0 & - & 212,4 \\
\hline $\begin{array}{l}\text { Центральный } \\
\text { Федеральный } \\
\text { округ, всего }\end{array}$ & 5406,3 & 17,6 & 138,8 & 5424,6 & 17,7 & 138,7 & 5569,0 & 17,9 & 142,1 \\
\hline \multicolumn{10}{|l|}{ в том числе } \\
\hline $\begin{array}{l}\text { Белгородская } \\
\text { область }\end{array}$ & 531,5 & 9,8 & 343,4 & 542,6 & 10 & 350 & 593,4 & 10,7 & 382,1 \\
\hline $\begin{array}{l}\text { Брянская об- } \\
\text { ласть }\end{array}$ & 291,1 & 5,4 & 236 & 293,2 & 5,4 & 239,2 & 292,9 & 5,3 & 240 \\
\hline Владимирская & 354,7 & 6,6 & 252,4 & 369,1 & 6,8 & 264,2 & 386,1 & 6,9 & 277,8 \\
\hline Воронежская & 807,7 & 15 & 346,5 & 828,5 & 15,3 & 355,4 & 841,3 & 15,1 & 360,1 \\
\hline Ивановская & 154,5 & 2,9 & 149,0 & 159,8 & 2,9 & 155,2 & 163,4 & 3,0 & 159,7 \\
\hline Калужская & 253,8 & 4,7 & 251,2 & 269,1 & 5,0 & 266,5 & 305,9 & 5,5 & 301,5 \\
\hline Костромская & 108,1 & 2 & 165,2 & 108,0 & 2 & 165,8 & 108,3 & 2,0 & 167,1 \\
\hline Курская & 310,0 & 5,7 & 277,4 & 294,1 & 5,4 & 262,6 & 287,8 & 5,2 & 256,3 \\
\hline Липецкая & 254,6 & 4,7 & 219,9 & 255,0 & 4,7 & 220,6 & 257,0 & 4,6 & 222,3 \\
\hline Московская & 631,1 & 11,7 & 87,3 & 627,5 & 11,6 & 85,7 & 644,3 & 11,6 & 86,7 \\
\hline Орловская & 183,9 & 3,4 & 240,3 & 178,0 & 3,3 & 234,3 & 172,4 & 3,1 & 228,4 \\
\hline Рязанская & 365,1 & 6,8 & 312,5 & 374,9 & 6,9 & 331,8 & 398,1 & 7,2 & 353,3 \\
\hline Смоленская & 218,1 & 4,0 & 226,1 & 207,9 & 3,8 & 216,9 & 199,1 & 3,6 & 208,9 \\
\hline Тамбовская & 220,3 & 4,1 & 207,4 & 200,2 & 3,7 & 190,6 & 194,9 & 3,5 & 187,4 \\
\hline Тверская & 213,5 & 4,0 & 162,3 & 212,6 & 4,0 & 163,0 & 214,1 & 3,8 & 165,1 \\
\hline Тульская & 187,3 & 3,5 & 123,7 & 185,8 & 3,4 & 123,3 & 170 & 3,1 & 113,4 \\
\hline $\begin{array}{l}\text { Ярославская } \\
\text { область }\end{array}$ & 280,7 & 5,2 & 220,7 & 293,6 & 5,4 & 230,8 & 310,2 & 5,6 & 244,1 \\
\hline
\end{tabular}




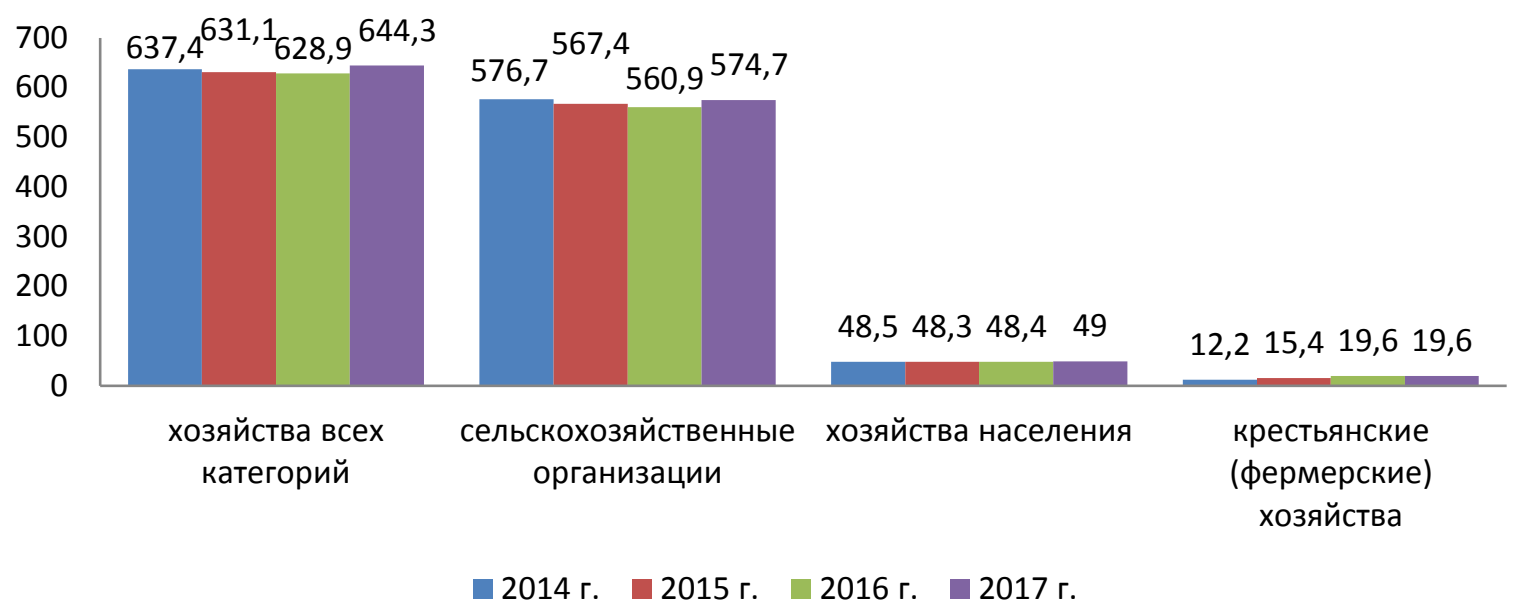

Puc. 1. Динамика производства молока по отдельным категориям хозяйств в Московской области за период 2014-2017 гг., тыс.тонн

Таблица 2. Поголовье молочного стада в хозяйствах Московской области в 2014-2016 гг., тыс. голов

\begin{tabular}{|c|c|c|c|c|}
\hline Наименование & 2014 г. & 2015 г. & 2016 г. & 2017 г. \\
\hline Российской Федерации, млн.голов & 8,4 & 8,4 & 8,3 & 8,2 \\
\hline ЦФО, тыс.голов & 1172,7 & 1168,1 & 1169,2 & 1182,8 \\
\hline $\begin{array}{l}\text { Поголовье коров в хозяйствах всех категорий } \\
\text { в Московской области, всего } \\
\text { в том числе: }\end{array}$ & 103,0 & 99,8 & 97,7 & 98,7 \\
\hline в сельскохозяйственных организациях & 94,2 & 89,4 & 87,0 & 85,5 \\
\hline в хозяйствах населения & 6,9 & 6,9 & 7,0 & 7 \\
\hline в крестьянских (фермерских) хозяйствах и ИП & 2,5 & 3,6 & 4,1 & 4,2 \\
\hline
\end{tabular}

личивается поголовье молочного стада. В области в 2017 году по сравнению с 2015 годом наблюдается незначительное сокращение численности дойного стада, но продуктивность коров растет, что позволяет увеличивать валовые надои молока и тем самым перекрывать сокращение количества коров. Экономические санкции позволили молочной промышленности региона нарастить объемы выпуска продукции. Следует отметить, что ООО Совхоз «Головково» входит в число крупнейших производителей молока в Московской области.

Московская область является третьей областью в России (после Ленинградской области и Москвы) по средней молочной продуктивности коров. Так, в 2017 г. по сравнению с 2016 годом надой молока на одну корову в хозяйствах всех категорий вырос на 2,9\% и составил 6560 кг (рис. 2).

Увеличение продуктивности коров в области связано как с увеличением доли племенного поголовья, так и с улучшением кормовой базы. Значительный вклад в совершенствование ге- нетического потенциала вносят предприятия по искусственному осеменению сельскохозяйственных животных. Среди таких предприятий можно отметить ОАО «Головной центр по воспроизводству сельскохозяйственных животных», ОАО «Московское». Значительных результатов относительно молочной продуктивности коров достигли ОАО «Предприятие «Емельяновка»» (10683 кг.), СПА «Кузьминский» (10269 кг.), ОАО «Агрофирма «Сосновка»» (9821 кг.).

Лидерами по производству и реализации молока в Московской области являются ООО «РусМолоко», ООО Племзавод «Барыбино» (производство 27 тыс.тонн молока в год), ГУП НПО «Пойма» (14,5 тыс.тонн молока в год), ООО «Шеметово» (13 тыс.тонн молока в год), ЗАО ПЗ «Наро-Осановский» (АО «Агроплемсоюз») (12 тыс.тонн в год).

В Московской области производится 86,7 кг молока в расчете на душу населения, его потребление составляет 248 кг при научно обоснованной медицинской норме 325 кг молока. Так, в 2017 г. по сравнению с 2015 годом произошло 


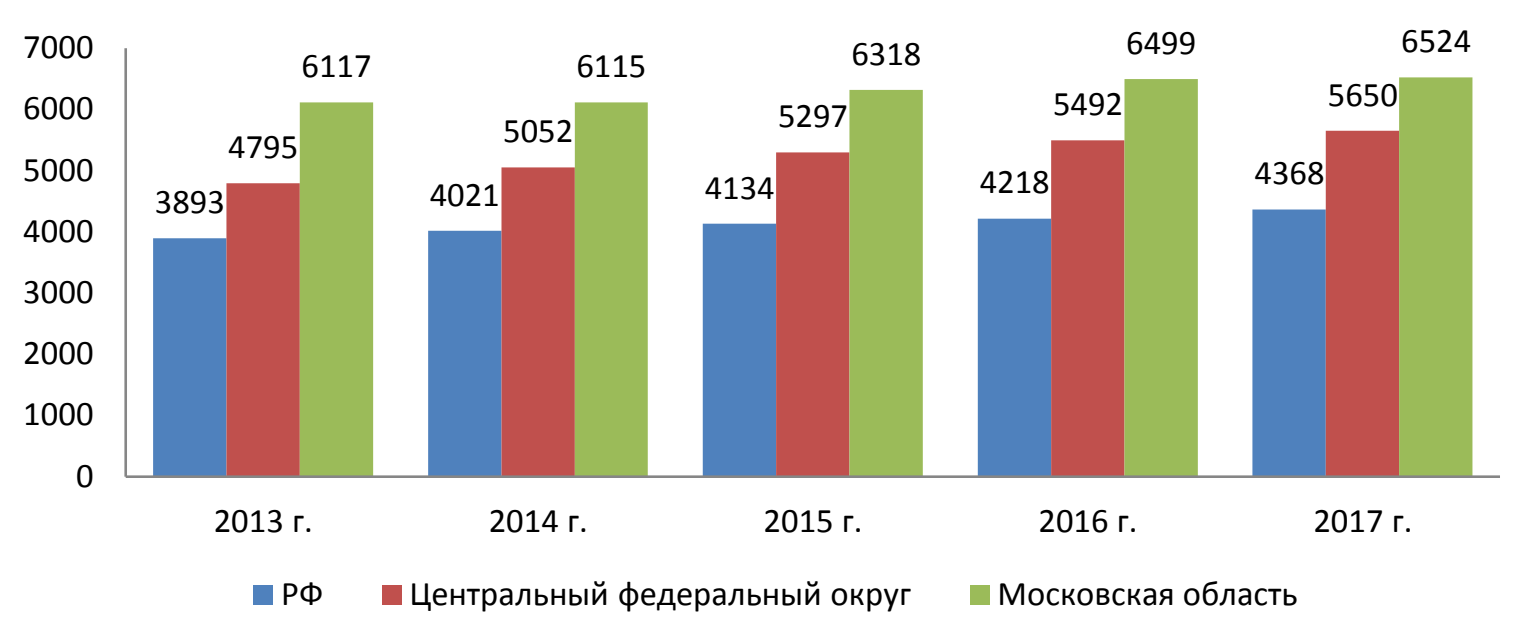

Puc. 2. Надои молока на одну корову в Московской области за период 2014-2017 г., кг.

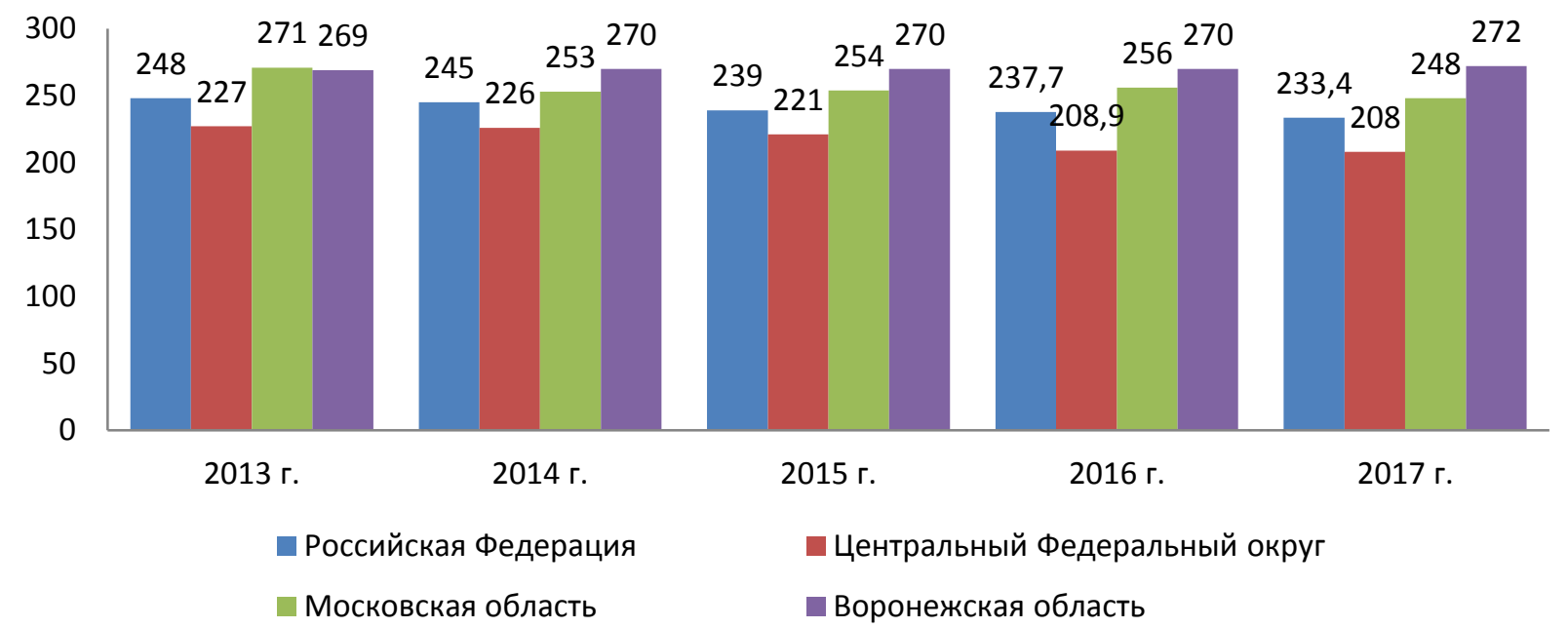

Puc. 3. Динамика потребления молока и молокопродуктов на душу населения за 2013-2017 гг., кг/г.

снижение потребления населением молочной продукции в среднем на 2,4\%. (рис. 3).

Потребление молочной продукции в Московской области за 2013-2017 гг. демонстрировало тенденцию к его сокращению. Причиной подобной динамики является изменение потребительских предпочтений в результате снижения покупательной способности денежных доходов населения (сохранение номинального уровня заработной платы при повышении цен и уровня инфляции), повышения цен на молочную продукцию во втором полугодии и увеличения стоимости импорта в результате роста мировых цен. В процессе ценообразования торговые сети устанавливают наценку на молоко и молочную продукцию до $70 \%$ к цене от производителя. По структуре потребления на рынке наблюдается тенденция увеличения спроса на более доступные молочные продукты, такие как сырные продукты, спреды, молоко, кефир.

В настоящее время основными потребителями сырого молока являются компании, занимающиеся переработкой молока и производством молочной продукции, находящиеся в Московской области. При этом производимого в области молока не хватает перерабатывающим предприятиям для выполнения планов производства, что приводит к закупкам сырого молока в других регионах России. По данным Министерства сельского хозяйства и продовольствия Московской области сельскохозяйственные товаропроизводители всех категорий обеспечивают молоком и молочными продуктами только $41 \%$ населения региона. Недостающие потребности в молоке компенсируются за счет импорта, который составляет около 1,2 млн.тонн. Уровень самообеспеченности населения Центрального федерального округа молоком и молочными 
продуктами составляет $59 \%$.

Московская область является лидером по объему переработки молока, одновременно являясь крупнейшим регионом-импортером сырого молока. В 2017 г. предприятия Московской области переработали 1282000 тонн молока, что на 4,23\% больше, чем в 2016 году. Область возглавляет рейтинг дефицитных регионов с точки зрения промышленного потребления, разница между объемом переработки и производства молока составляет 637700 тонн, что на 36300 тонн меньше, чем в 2016 году. Также область возглавляет рейтинг дефицитных регионов по молоку-сырью с точки зрения потребления на душу населения (-4-5 млн. тонн). В 2017 г. экспорт молока и молочной продукции предприятий Московской области составил 10,7 тысячи тонн. Московская область поставляет небольшой объем кисломолочной продукции и молочных консервов в Среднюю Азию, Казахстан, Китай. Молочная продукция импортируется из Белоруссии, Казахстана, Новой Зеландии, Аргентины, Турции, Уругвай.

По оценкам специалистов, российский рынок молока и кисломолочной продукции сформирован примерно на 90\%. Лидеры - компании российского молочного рынка АО «Вимм-Бил-
ль-Данн», АО «Данон Россия», АО «Молвест», ООО «Эрманн», ОАО «Компания Юнимилк», ОоО «Campina» занимают около 50\% рынка.

Молочная промышленность Московской области представлена 70 крупными, средними и малыми предприятиями различной формы собственности, в том числе 21 предприятие составляют молочные заводы и цеха по производству молочной продукции при сельскохозяйственных организациях.

В Московской области расположены 4 крупных молокоперерабатывающих завода, с мощностью производства более 200 тонн в сутки: ЗАО «Дмитровский молочный завод» (Дмитровский муниципальный район); ООО «Эрманн» (Раменский муниципальный район); ООО «Кампина» (Ступинский муниципальный район); ООО «Данон индустрия» (Чеховский муниципальный район). Значительная доля на рынке по переработке молока в Московской области принадлежит ОАО Лианозовскому молочному комбинату компании РерsiCo (табл. 3, рис. 4).

По итогам 2017 года рентабельность производства молока составила в пределах 15-25\%.

В области сосредоточено почти $4 \%$ всех российских мощностей по производству цельномолочной продукции, 11\% мощностей по произ-

Таблица 3. Суточная производственная мощность крупных молокоперерабатывающих заводов Московской области

\begin{tabular}{|l|c|c|}
\hline \multicolumn{1}{|c|}{ Наименование предприятия } & $\begin{array}{c}\text { Суточная производственная } \\
\text { мощность, тонн }\end{array}$ & $\begin{array}{c}\text { Объем переработки молока } \\
\text { в год }\end{array}$ \\
\hline ОАО «Лианозовский молочный комбинат» & 1500 & 1430 тыс.тонн \\
\hline ООО «Данон-Индустрия» & 800 & 1418 тыс.тонн \\
\hline ОАО «Останкинский молочный завод» & 350 & 104200 тонн \\
\hline ЗАО «Дмитровский молочный завод» & 280 тонн & 78500 тонн \\
\hline ООО «Кампина» & 218 тонн \\
\hline
\end{tabular}

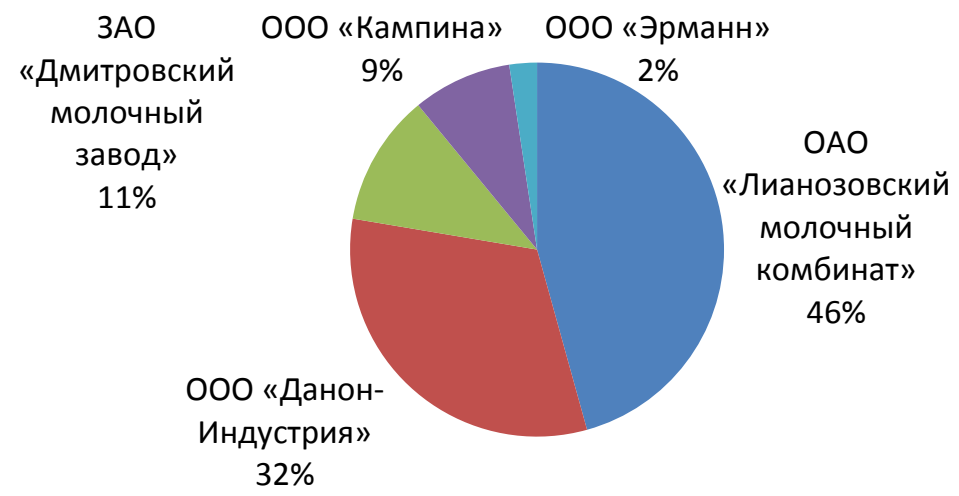

Puc. 4. Рейтинг молокоперерабатывающих заводов по объемам переработки молока в Московской области. 
водству сыра и сырных продуктов, а также около 95\% производственных мощностей по выпуску сухих молочных смесей, включая кисломолочные, для детей раннего возраста. Использование мощностей - около $60 \%$.

Объемы производства основных видов молочной продукции приведены в табл. 4. Таким образом, по данным таблицы можно сделать вывод о том, что в 2017 г. производство цельномолочной продукции увеличивается по сравнению с 2016 годом на 0,5\%, масло сливочное - на $61,3 \%$.

В области функционируют сельскохозяйственные предприятия, осуществляющие собственную переработку молока: Агрохолдинг ОАО «Рузское молоко», ООО «Братья Чебурашкины», ООО «Племзавод «Барыбино», АО АИСФеР, АО «Племхоз «Наро-Осановский», ООО «АПК Шатурский», ФГУП «АПК «Непецино», АО «Зеленоградское», ЗАО «Шестаково».

Исследуемая область лидирует по объемам производства творожных продуктов, йогуртов, мороженого, а также сухих молочных смесей для маленьких детей. Рост производства некоторых видов молочной продукции вызвано использованием при их выработке различных наполнителей растительного происхождения и лучшего использования вторичного сырья.

Рынок сыров - один из самых перспективных и привлекательных на продовольственной площадке страны. В настоящее время производством сыров в Московской области занимается более 40 предприятий, в том числе 14 фермерских хозяйств. Доля продукции фермерских хозяйств в области составляет 3\%. Московская область лидирует в Центральном федеральном округе по производству сыра и сырных продуктов, а также занимает по данному показателю второе место в России.

Производство плавленых сыров в Московской области осуществляют ООО «Лакталис Истра» (Истринский муниципальный район); ООО «Валио» (филиал Ершово) (Одинцовский муниципальный район); ООО «Хохланд Рус- сланд» (Раменский муниципальный район).

В структуре производства сыров и сырных продуктов по типам наибольшую долю занимают твердые сыры (24\%) и сырные продукты (24\%), полутвердые сыры (19\%), плавленые сыры (17\%) и прочие типы сыров. Увеличение объемов производства сырных продуктов в течение последних нескольких лет объясняется повышением спроса на сравнительно недорогие «сыры» в условиях сокращения реальных располагаемых доходов населения.

B рамках политики импортозамещения и реализации мероприятий государственной программы «Сельское хозяйство Подмосковья» (на 2014-2020 г.), утвержденной постановлением Правительства Московской области от 13.08.2013 г № 602/31, в 2018 году на территории ГУП МО «Агрокомплекс «Яхромский»» в Дмитровском районе осуществляется создание сырного кластера с объемом производства 12,5 тысяч тонн продукции в год.

В области распространяется ряд мер поддержки на молочное животноводство, в их числе субсидия на килограмм молока, субсидия на содержание племенного животного, которая в 2018 году составляет 14 тыс. рублей на голову. На поддержку молочной отрасли в Московской отрасли в текущем году выделено 1,5 миллиарда рублей. При строительстве новых животноводческих комплексов в Московской области численностью более четырехсот голов, федеральная часть компенсации составляет 35\% от капитальных затрат, при этом минимальный уровень софинансирования из регионального бюджета составляет 5\%. При строительстве животноводческих комплексов численностью менее четырехсот голов, а также от ста до четырехсот голов, капитальные затраты компенсируются за счет регионального бюджета и ставка субсидий составляет 20\%. Кроме того, ставка субсидий на приобретение племенного поголовья составляет 110 рублей за килограмм живого веса. Данный скот должен быть племенным, высокопродуктивным и отвечать всем необходимым требо-

Таблица 4. Динамика производства основных видов молочной продукции в Московской области 2015-2017 гг., тыс.тонн

\begin{tabular}{|l|c|c|c|}
\hline \multicolumn{1}{|c|}{ Наименование } & 2015 г. & 2016 г. & 2017 г. \\
\hline Цельномолочная продукция (в пересчете на молоко) & 390,9 & 380,1 & 382 \\
\hline Масло сливочное & 0,68 & 0,62 & 1,0 \\
\hline Сыры и сырные продукты & 50 & 50 & 50 \\
\hline Йогурт & 404,9 & 395,2 & 380 \\
\hline
\end{tabular}


ваниям, в том числе и ветеринарного законодательства РФ. Размер субсидий на «повышение продуктивности молочного стада» варьируется в зависимости от продуктивности поголовья: от полутора рублей для низкопродуктивного скота, до двух рублей для высокопродуктивного скота. Субсидия на содержание племенного маточного поголовья крупного рогатого скота молочного направления продуктивности составляет 5800 рублей на голову из регионального бюджета.

В Московской области реализуются специальные программы по поддержке производителей сыра. Основной мерой поддержки является получение грантов предпринимателями, которые осуществляют строительство мелких сыроварен. Так, в 2018 году производителям сыра выделены сто миллионов рублей. При этом в регионе сыроварам безвозмездно выделяется земля в аренду. Кроме того, в Московской области существует федеральная программа субсидирования процентной ставки. В 2017 году в Подмосковье ввели программу по возмещению из регионального бюджета $20 \%$ капитальных затрат для сыроваров.

Подавляющая часть потребителей готовой молочной продукции, производимой на территории Московской области, находится за его пределами. Большая часть из них приходится на традиционные рынки сбыта продукции - peгионы Сибири и Дальнего Востока, часть - на Уральский ФО России.

Если рассматривать более отдаленные от Московской области регионы России, то важно отметить, что подавляющую часть экспорта будет составлять молочная продукция с длительным сроком годности, а именно сливочное масло, сыры, мороженое и сухое молоко, что связано со сроками транспортировки продукции.

Крупными производителями плавленых сыров в области являются ОАО Московский завод плавленых сыров «Карат», ООО «Хохланд Руссланд», ООО «Лакталис Истра», ООО «Валио» (филиал Ершово). По данным вторичных продаж сетей ОАО «Карат» входит в тройку крупнейших производителей плавленого и творожного сыра в России. Завод осуществляет политику качества международным сертификатом качества ISO 9001:2015.

Для дальнейшего развития рынка молока и молочной продукции в Московской области необходимо:
- увеличить производство и товарность молока-сырья, повысить качество и ликвидировать сезонность его производства;

- осуществлять систематическую реконструкцию и модернизацию существующих животноводческих помещений;

- обеспечить вовлечение в хозяйственный оборот вторичных ресурсов, получаемых при производстве молочных продуктов;

- расширить ассортимент выпускаемой продукции с повышенной пищевой и биологической ценностью за счет применения новых видов упаковочных материалов;

- обеспечить концентрацию производства за счет создания нескольких молокоперерабатывающих заводов мощностью по переработке молока не менее 1,0 тыс. тонн в сутки;

- увеличить долю выпуска молочных продуктов для детского, диетического (лечебного и профилактического) питания, обогащенных витаминами и минеральными веществами, до 45\% общего объема производства цельномолочной продукции;

- продолжить деятельность по созданию селекционно-генетического центра в молочном скотоводстве;

- ежегодно проводить отраслевые конкурсы профессионального мастерства (операторы машинного доения, зоотехники-селекционеры);

- повысить культуры производства племенных хозяйств, качества кормов собственной заготовки, уровня воспроизводства и сохранности молодняка;

- создавать молочные кластеры, ядром которых станут молочные заводы с возможностью переработки молока не менее 1,0 тыс. тонн в сутки;

- систематически повышать квалификацию специалистов отрасли животноводства;

- стимулировать потребление молока и молокопродуктов через программу внутренней продовольственной помощи и развития инфраструктуры системы социального питания; программы стимулирования потребления молока и молочных продуктов (по аналогии с программой Союзмолоко «Три молочных продукта в день»).

- ужесточить ответственность (кратное увеличение штрафов) за нарушение технического регламента ЕАЭС в части маркировки молочной продукции, в частности за отсутствие на этикетке информации о наличии жиров немолочного 
происхождения и реализации молокосодержащей продукции под видом молочной;

- сократить влияния сезонного фактора на ценовую конъюнктуру молочного рынка в сезон «большого молока» путем скорейшего запуска механизма закупочных и товарных интервенций [7] в отношении сухого молока и сливочного масла.

Комплексное решение обозначенных задач позволит обеспечить восстановление и развитие молочной отрасли, создать условия для увеличения объемов производства молока и молочных продуктов, снизить количество некачественной молочной продукции.

\section{Библиографический список}

1. Молочная отрасль-2017: [справочник] / сост.: А.С. Белов, А.А. Воронин, М.Э. Жебит [и др.] Москва. 2017. 380 c.

2. Московская область: статистический сборник / Территориальный орган Федеральной службы государственной статистики по Московской области. Москва.2017. 52 с.

3. Майоров А.А. Анализ современных тенденций в производстве молочных продуктов / Майоров А.А., Сурай Н.М. // Аграрная наука - сельскому хозяйству. Сборник статей: в 3 книгах. Алтайский государственный аграрный университет. 2016. С. 254-258.

4. Сурай Н.M. Анализ потребления молока и молочных продуктов в России и Московской области / Сурай Н.М., Неверов П.А., Жукова Н.В.// Модернизация экономических систем: взгляд в будущее (MESLF-2017) Сборник научных трудов Международной научно-практической конференции. Под редакцией П.А. Неверова, Б.А. Аманжоловой. 2017. С. 79-84.

5. Сурай Н.М. Маркетинговый анализ регионального рынка сыра / Сурай Н.М., Стерликов Ф.Ф., Майоров А.А. // Экономические науки. 2017. № 149. С. 64-69.

6. Официальный сайт Территориального органа Федеральной службы государственной статистики по Московской области www/msko.gks.ru

7. Стерликов Ф.Ф. Экономическая теория ценности блага как интегратор трудовой теории стоимости и теории предельной полезности. Вопросы экономики и права. 2012. № 50. С. 27-31. 